\title{
Brief Report \\ The Potential of Biochar to Enhance the Water Retention Properties of Sandy Agricultural Soils
}

\author{
Elizaphan Otieno Ndede ${ }^{1,2}\left(\mathbb{D}\right.$, Soboda Kurebito ${ }^{2}$, Olusegun Idowu ${ }^{3}$, Takeo Tokunari ${ }^{1,4,5}$ and Keiji Jindo ${ }^{6, *(\mathbb{D})}$ \\ 1 Agriculture and Rural Development, Japan International Cooperation Agency (JICA), Kenya Office, \\ P.O. Box 50572, Nairobi 00200, Kenya; otindede@gmail.com (E.O.N.); ttokunari@mde.harvard.edu (T.T.) \\ 2 Meiwa Co., Ltd., 3-8-1 Minato, Kanazawa-City 920-0211, Ishikawa, Japan; b-so@meiwa-ind.co.jp \\ 3 Division of Agronomy and Horticultural Science, Graduate School of Agriculture, Kyoto University, \\ Kyoto 606-8502, Japan; idowu.olusegun.adejola@gmail.com \\ 4 Harvard John A. Paulson School of Engineering and Applied Sciences, Science and Engineering Complex, \\ 150 Western Avenue, Boston, MA 02134, USA \\ 5 Harvard Graduate School of Design, 48 Quincy Street, Cambridge, MA 02138, USA \\ 6 Agrosystems Research Group, Wageningen University and Research, 6708 PB Wageningen, The Netherlands \\ * Correspondence: keiji.jindo@wur.nl
}

check for updates

Citation: Ndede, E.O.; Kurebito, S.; Idowu, O.; Tokunari, T.; Jindo, K. The Potential of Biochar to Enhance the Water Retention Properties of Sandy Agricultural Soils. Agronomy 2022, 12, 311. https://doi.org/10.3390/ agronomy12020311

Academic Editors: Guopeng Liang, Yuan Li and Andong Cai

Received: 29 December 2021

Accepted: 21 January 2022

Published: 25 January 2022

Publisher's Note: MDPI stays neutral with regard to jurisdictional claims in published maps and institutional affiliations.

Copyright: (c) 2022 by the authors. Licensee MDPI, Basel, Switzerland. This article is an open access article distributed under the terms and conditions of the Creative Commons Attribution (CC BY) license (https:// creativecommons.org/licenses/by/ $4.0 /)$

\begin{abstract}
The impact of climate change has become increasingly severe in drylands, resulting in heat stress and water deficiency and, consequently, reducing agricultural production. Biochar plays an important role in improving soil fertility. The properties of sandy soils where water deficiency occurs with a greater frequency need to be enhanced by biochar amendments to increase the water retention capacity (WRC). Few studies have reported the effects of biochar on the readily available water (RAW) of these soils or an evaluation of the optimal application rate of the biochar. In this study, we aimed to assess the effect of different biochar types and application rates on the soil properties related to water retention. Under laboratory conditions, we amended sandy soil with four different types of biochar (woodchip (WBC), waterweed of Ludwigia grandiflora (WWBC), poultry litter (PLBC) and bagasse (BBC)) at rates of $0 \%, 5 \%, 10 \%, 15 \%, 25 \%, 50 \%, 75 \%$ and $100 \%$. Soils treated with zeolite and perlite, both conventional materials, were arranged for a comparative study. The water content in the amended soils was recorded at saturation, field capacity, wilting point and oven-dry. Our results show a reduction in the bulk density by increasing the amendment rate across all biochar types. Although the WRC increased with the application rate, the RAW reduced and peaked at a 5\% $(v / v)$ biochar content for almost all the biochar types. WBC and WWBC showed the highest RAW increments of $165 \%$ and $191 \%$, respectively, at a $10 \%(v / v)$ rate. In most cases, higher rates (such as $75 \%(v / v)$ of PLBC) caused negative effects on the RAW. Following these results, it is clear that both the biochar type and the application rate significantly influence the hydrological properties and the RAW capacity of sandy soils. A 5\% $(v / v)$ biochar amendment could significantly improve the readily available water to mitigate drought in sandy agricultural soils.
\end{abstract}

Keywords: biochar; soil amendment; readily available water; drought; sandy soils

\section{Introduction}

Recently, climate change and the related impacts-for example, drought-have become more severe and widespread across the globe, especially in arid and semi-arid regions (ASALs) [1]. Rainfall is becoming irregular, average temperatures are generally rising and land and water resources deteriorate daily, resulting in heavy agricultural losses [2]. These situations present most regions with the cruel reality of frequent extreme climate events, associated hunger and rampant poverty. In addition, the global population is projected to rise to almost 10 billion people by the year 2050 [3], which may further stress the food systems. As the situation worsens, there is an increased need to explore interventions to improve food security amidst these impactful events to save humanity and the planet alike. 
Emerging concepts such as climate-smart agriculture (CSA) gain traction as nextgeneration interventions to intensify food production with reduced climate impacts. As such, climate change adaptation has become key in modern-day farming activities. The proper management of soil and water resources and the adoption of smart cropping systems are considered to be helpful in this approach [4]. In this regard, drought mitigation is crucial both in rain-fed and irrigated agriculture. Therefore, farming systems should embrace activities that improve water retention and efficiency through on-farm water management interventions. This is an initial step toward the conservation of this diminishing resource.

One of the most common agricultural practices is the use of soil conditioning materials to ameliorate sandy soils that are often less able to retain water. These materials can improve the water retention of agricultural soils, among other benefits. Previous studies have indicated that products such as zeolite and superabsorbent polymers (SAP) can improve water retention in agricultural soils on a limited scale [5-10]. Apart from their minimal effect on the retention of available water, most of them also have a short lifespan in the soil [11]; a few are inorganic and are usually costly to the average farmer. Therefore, there is a need for alternative amendment materials that are sustainable from economic and ecological viewpoints. Biochar, a highly porous carbonaceous product of biomass pyrolysis, provides multifunctionalities in the agricultural and ecological sectors [12]. It can be produced from any organic materials that would otherwise be wasted, such as crop harvest residues or by-products of food processing [13]. Bagasse, maize stalks, maize cobs, coffee husks, rice husks and livestock manure are well-known feedstocks that can be carbonized for biochar production [14,15].

Biochar is a high carbon sequester and climate change mitigation agent [16] and is believed to improve nutrient retention and ameliorate soil water conditions, leading to improved crop performances [12,17-19]. These benefits result from its amendment impacts on the soil as dictated by its physicochemical characteristics $[20,21]$, which vary with the feedstock and pyrolysis process [22]. The heating temperature during the pyrolysis process is one of the critical factors to determine the biochar property. An elevated temperature typically creates a biochar product with a greater carbon content along with a high microsurface and pore volume, whereas a lower temperature produces another type with a more volatile content [23]. Physical properties such as the particle size/shape, porosity, the total volume of pores (especially equivalent to the RAW) and the specific surface area are essential for the enhancement of soil fertility [24,25]. Various studies have reported that biochar can increase the soil water retention capacity (WRC) [24-27]. With such improved hydraulic properties, agricultural soils can hold a greater amount of water for longer [28], which can then reduce irrigation requirements and frequency.

Although it is essential to manage the soil to hold a greater amount of water, soil water is of greater use when freely held for effective crop uptake [29]. Thus, whether and how the interactions between biochar and the amended soil help to create such a condition need to be studied with greater discernment. Numerous studies have tested and reported the impact of amending agricultural soils with various biochar types on the soil properties and WRC [24-27] but only a few have investigated the effects of plant-available water [30,31] on poor soils such as sandy soil. Basso et al. [26] conducted a study on the WRC of sandy loam amended with hardwood biochar. They discovered that the WRC increased by up to $84 \%$ and $38 \%$ for biochar addition rates of $3 \%$ and $6 \%(w / w)$, respectively. As in most of the other studies, they pointed out that such biochar amendments improved the RAW capacity of the studied soil. However, the mechanism and extent of this effect on different feedstocks were not entirely clear. These effects are believed to be influenced by the physical characteristics of the biochar type used; properties such as the particle size and shape were reported by Liu et al. [25] to be influential on soil hydrology. In this study, we investigate how sandy soils would interact with varying amounts of biochar from different feedstocks, analyze the resulting impact on the readily available water (RAW) capacity and provide a comparison with the existing soil conditioners zeolite and perlite. 


\section{Materials and Methods}

\subsection{Soil Sample}

A soil sample was collected from a biochar-free farm in Awagasaki, Kanazawa City, Japan $\left(36^{\circ} 37^{\prime} 15^{\prime \prime} \mathrm{N}, 136^{\circ} 36^{\prime} 59^{\prime \prime} \mathrm{E}\right)$, in gunny bags to protect it from contamination during transportation and storage. It was then cleaned of unwanted solid materials and air-dried in a greenhouse to below a $10 \%$ moisture content before sieving through a $2.0 \mathrm{~mm}$ mesh. The soil sample was analyzed using a pipette [32] and its particle size distribution was classified as fine sandy soil based on a textural triangle with $97.1 \%$ sand, $0.0 \%$ silt and $2.9 \%$ clay contents.

The dry bulk density $\left(\rho_{b}\right)$ was determined by filling a $100 \mathrm{~cm}^{3}$ stainless steel cylindrical can with the soil sample and oven-drying it at $105^{\circ} \mathrm{C}$ in a Yamato Drying Oven (DV41) for $24 \mathrm{~h}$. The sample was weighed and its mass was determined. Equation (1) below was then applied to compute $\rho_{b}$ :

$$
\rho_{b}=\frac{M_{d}}{V} \mathrm{~g} \mathrm{~cm}^{-3}
$$

where $M_{d}$ is the mass of the oven-dry sample and $V$ is the total volume of the can. The computed $\rho_{b}$ of the studied soil was $1.408 \mathrm{~g} \mathrm{~cm}^{-3}$.

\subsection{Biochar Sample}

The production of biochar was conducted at Meiwa Co., Ltd. in Kanazawa City, Ishikawa Prefecture, Japan. The biochar used in this study was produced from woodchips (WBC), bagasse (BBC), pelletized poultry litter (PLBC) and waterweed Ludwigia grandiflora (WWBC). The sample of WBC, which was a woodchip of Japanese cedar, was acquired from the Kidagen Company, Ro-52, Sano Town, Nomi City, Ishikawa Prefecture, 923-1112, Japan. The sample of PLBC was obtained from the Oka Poultry Company, 952-1, Myojin, Nikko City, Tochigi Prefecture, 321-1101, Japan. Ludwigia grandiflora was sampled from Biwa Lake and dried for biochar production. All the materials were well dried and then pyrolyzed using a batch-type carbonizer "Carbon Box" (width: $2250 \mathrm{~mm}$; length: $6250 \mathrm{~mm}$; height: $2100 \mathrm{~mm}$ ) and a small improvised electric carbonizer (of approximately a 10 L capacity). These two products were in-house biomass carbonization technologies of Meiwa Co., Ltd. (https: / / www.meiwa-ind.co.jp/en/ (accessed on 14 January 2022)). The temperature of the pyrolysis was approximately 450 to $500{ }^{\circ} \mathrm{C}$. The heating time was $7 \mathrm{~h}$ and the cooling time to reach $100{ }^{\circ} \mathrm{C}$ was $8 \mathrm{~h}$. An anaerobic environment was achieved by: (1) keeping the carbonization chamber of the ECO5000 tightly closed using packing and screws; and (2) continuously purging the oxygen by carbonized gas generated from the feedstock during carbonization. The continuation of the anaerobic environment was confirmed by visually observing the sustained supply of carbonized gas from the carbonization chamber to the combustion chamber where the gas was combusted as an extra energy source to further heat the carbonization chamber.

The produced biochar was stored separately in sealed plastic bags according to the feedstock type and later air-dried and sieved to the required particle size. In this study, biochar samples with a particle size of $0.5-1.0 \mathrm{~mm}$ were used after homogenously being sieved. The prepared biochar samples were again stored in sealed plastic bags and later mixed with the soil sample to form a uniform substrate sample. Table 1 shows a few of the relevant properties of the various biochar samples used in this study.

Table 1. Properties of the biochar samples produced from woodchips (WBC), bagasse (BBC), pelletized poultry litter (PLBC) and waterweed Ludwigia grandiflora (WWBC).

\begin{tabular}{ccccc}
\hline Property & \multicolumn{4}{c}{ Biochar Type } \\
\cline { 2 - 5 } & WBC & BBC & PLBC & WWBC \\
\hline Pyrolysis temperature $\left({ }^{\circ} \mathrm{C}\right)$ & $450-500$ & $450-500$ & $450-500$ & $450-500$ \\
Bulk density $\left(\mathrm{g} \mathrm{cm}^{-3}\right)$ & 0.107 & 0.054 & 0.583 & 0.263 \\
Specific surface area $\left(\mathrm{m}^{2} \mathrm{~g}^{-1}\right)$ & 361.5 & 29.4 & 9.5 & 29.4 \\
Peak pore size $(\mathrm{nm})$ & 0.63 & 0.80 & $1.00-2.00$ & 1.50 \\
\hline
\end{tabular}




\subsection{Zeolite and Perlite}

Zeolite and perlite are two commercial amendment materials that were used in this study for a comparison with the biochar types. Zeolite was procured from Akagi Horticulture Co., Ltd. Nagano, Japan and perlite from Iseki \& Co., Ltd. Kanazawa, Japan. These materials are already in use by farmers as soil conditioners in different regions. Following the manufacturer's recommendation of $5 \%$ zeolite and $10 \%$ perlite $(v / v)$, the samples were measured and homogeneously mixed with the soil samples.

\subsection{Experiment Design}

The soil sample was amended with biochar rates of $0 \%, 5 \%, 10 \%, 15 \%, 25 \%, 50 \%, 75 \%$ and $100 \%(v / v)$. Each substrate sample was poured into stainless steel cylindrical cans with a volume of approximately $100 \mathrm{~cm}^{3}(5.03 \mathrm{~cm}$ diameter and $5.03 \mathrm{~cm}$ height). Each was then mixed manually by careful stirring to achieve a proper homogeneity of the mixture. The resulting substrates were set up in a completely randomized laboratory experimental design with four replicates each. The water retention of the biochar and soil-biochar samples was analyzed using a series of simple hydrostatic column experiments [33] based on the guidelines of the Ministry of Agriculture, Forestry and Fisheries, Tokyo, Japan. In addition to the saturation point (suction) $(\mathrm{pF}=0)$, the water content was determined at the field capacity $(\mathrm{FC})(\mathrm{pF}=1.5)$ and depletion point $(\mathrm{DP})(\mathrm{pF}=2.7)$ using a similar sand (hanging water) column and ceramic tension plates, respectively.

The cans containing the samples were set up in a shallow basin of water for $24 \mathrm{~h}$ to achieve a uniform saturation by capillary rise. The mass of the amended soil with the biochar was recorded (mass at $\mathrm{pF}=0$ ) before they were transferred onto the sand column for $48 \mathrm{~h}$. Again, the mass of each sample (mass at $\mathrm{pF}=1.5$ ) was noted. They were then set up on dry ceramic plates and covered for another $48 \mathrm{~h}$ and the mass (mass at $\mathrm{pF}=2.7$ ) was recorded before oven-drying in a Yamato Drying Oven (DV41) for a further $24 \mathrm{~h}$. The masses of the can and the sample were recorded before weighing the can alone. The gravimetric water content $\left(\theta_{g}\right)$ of each sample was computed and multiplied by the corresponding bulk density $\left(\rho_{b}\right)$ to obtain the respective volumetric water content $\left(\theta_{v}\right)$ in $\mathrm{cm}^{3} \mathrm{~cm}^{-3}$. The WRC and its effective portion, the RAW capacity, affected by each treatment at the FC were then computed by Equation (2) and Equation (3), respectively:

$$
W R C\left\{\theta_{v}=\frac{M_{w}}{M_{d}} \times \rho_{b}\right\} \times 100 \%
$$

where $M_{w}$ is the mass of the total retained water at the field capacity calculated by the difference between the mass of the sample at the FC $\left(M_{\mathrm{pF}=1.5}\right)$ and that of an oven-dry sample $\left(M_{o s}\right)$ and:

$$
\operatorname{RAW}\left\{\theta_{v}=\frac{M_{e f f}}{M_{d}} \times \rho_{b}\right\} \times 100 \%,
$$

where $M_{e f f}$ is the mass of the retained water effective for plant use. It was computed by subtracting the mass of the sample at the DP $\left(M_{\mathrm{pF}=2.7}\right)$ from that at the FC $\left(M_{\mathrm{pF}=1.5}\right)$.

\subsection{Statistical Analysis}

An analysis of variance (ANOVA) for the RAW data was performed using the $\mathrm{R}$ program (3.5.1 version, RStudio Inc., Boston, MA, USA). A Tukey's honest significant difference (HSD) test was conducted to analyze the significant variations and comparisons among the data of the pairwise treatments. All measurements were conducted with four replications for each sample. All other statistical calculations were performed in Microsoft Excel 2013; graphs and figures were prepared and drawn using SigmaPlot Software (v14.0, Systat Software, Point Richmond, CA, USA). 


\section{Results and Discussion}

\subsection{Bulk Density}

As shown in Table 1, we observed that the values of $\rho_{b}$ were in the reducing order of PLBC, WWBC, WBC and BBC. This was aligned with other previous studies such as Rajkovich et al. [34], which pointed out that biochar values are related to the $\rho_{b}$ of the respective parent feedstock. The trend was consistent with the results, as shown in Figure 1.



Figure 1. Effects of woodchip biochar (WBC), bagasse biochar (BBC), poultry litter biochar (PLBC) and waterweed biochar (WWBC) on bulk density (BD) by application rate $(v / v)$.

Bulk density is a direct function of porosity and specific surface area. In this study, PLBC depicted the highest $\rho_{b}$ with a considerably low specific surface area compared with that of wood-based biochar types (WBC and WWBC). This could be due to the shape of the biochar particles that were almost even in PLBC but quite rugged in the wood-based biochar types. Uneven biochar surfaces create a greater number of inter-particle pores that may result in a lower value $\rho_{b}[25,35]$.

Biochar amendments significantly reduced the bulk density of sandy soil (Figure 1), decreasing it consistently with every additional biochar application rate, as Abel et al. [36], Gamage et al. [37] and Obia et al. [38] had similarly reported previously. As biochar generally has a lower bulk density than sandy soil, the amendments resulted in a decrease in the bulk density of the sandy soil. This effect was more pronounced with higher application rates. All the biochar types and application rates affected a decrease in the $\rho_{b}$ value except for the $5 \%(v / v)$ addition of PLBC, which increased it by almost 3\%. The biochar addition of 5\% for WBC, BBC and WWBC showed a reduction of $4.5 \%, 3.1 \%$ and $2.6 \%$ in the values of $\rho_{b}$, respectively, compared to the control. The variation of the $\rho_{b}$ values was attributed to the physical properties of both the sand and biochar particles [39], which interacted and altered in the biochar-sand mixture.

\subsection{Water Retention Capacity and Readily Available Water Capacity}

Table 2 shows the ANOVA of the RAW as posted by each of the biochar types at various application rates. Generally, sandy soils have a low water retention ability, and this was affirmed in this study. The minimal proportion of fine-textured particles-silt $(0.0 \%)$ 
and clayey $(2.9 \%)$ - as well as the surface area of the smaller particles and the absence of effective pore sizes could have caused this [40]. When homogeneously blended, the sand-biochar mixture underwent aggregation that improved its physical structure; thus, it had the ability to hold a larger amount of water for a longer time.

Table 2. ANOVA for the readily available water (RAW) of sandy soil amended with biochar from woodchip (WCB), bagasse (BBC), poultry litter (PLBC) and waterweed (WWBC) at different application rates compared with zeolite and perlite.

\begin{tabular}{|c|c|c|c|c|c|c|}
\hline \multirow{2}{*}{$\begin{array}{c}\text { Application } \\
\text { Rate }(\%)\end{array}$} & \multicolumn{4}{|c|}{ RAW Content $\left(\mathrm{cm}^{3} \mathrm{~cm}^{-3}\right)$} & \multirow{2}{*}{ Mean } & \multirow{2}{*}{$\mathrm{CV}$} \\
\hline & WBC & BBC & PLBC & WWBC & & \\
\hline 5 & $0.085 \pm 0.009 a^{* * *}$ & $0.065 \pm 0.004 a^{* * *}$ & $0.059 \pm 0.001 a^{* * *}$ & $0.093 \pm 0.008 a^{* * *}$ & $0.076 a^{* * *}$ & 0.11 \\
\hline 10 & $0.085 \pm 0.002 a^{* * *}$ & $0.064 \pm 0.003 a^{* * *}$ & $0.058 \pm 0.002 a^{* * *}$ & $0.094 \pm 0.007 a^{* * *}$ & $0.075 \mathrm{ab} * *$ & 0.06 \\
\hline 15 & $0.078 \pm 0.010 b^{n . s}$ & $0.056 \pm 0.003 b^{n . s}$ & $0.056 \pm 0.002 b^{n . s}$ & $0.088 \pm 0.007 b^{* *}$ & $0.070 \mathrm{~b} *$ & 0.10 \\
\hline 25 & $0.074 \pm 0.009 \mathrm{bc}{ }^{\mathrm{n} . \mathrm{s}}$ & $0.047 \pm 0.003 b c^{n . s}$ & $0.040 \pm 0.005 b c^{n . s}$ & $0.069 \pm 0.011 \mathrm{~cd}^{\mathrm{n} . \mathrm{s}}$ & $0.057 c^{n . s}$ & 0.23 \\
\hline 50 & $0.064 \pm 0.002 \mathrm{c}^{\mathrm{n} . \mathrm{s}}$ & $0.041 \pm 0.005 c^{n . s}$ & $0.033 \pm 0.004 c^{n . s}$ & $0.053 \pm 0.006 \mathrm{~d}^{\mathrm{n} . \mathrm{s}}$ & $0.048 \mathrm{~cd}^{\mathrm{n} . \mathrm{s}}$ & 0.19 \\
\hline 75 & $0.050 \pm 0.003 d^{n . s}$ & $0.033 \pm 0.007 d^{n . s}$ & $0.026 \pm 0.004 d^{n . s}$ & $0.040 \pm 0.003 \mathrm{de}^{\mathrm{n} \cdot \mathrm{s}}$ & $0.037 \mathrm{~d}^{\mathrm{n} . \mathrm{s}}$ & 0.21 \\
\hline 100 & $0.031 \pm 0.001 \mathrm{e}^{\mathrm{n} . \mathrm{s}}$ & $0.022 \pm 0.002 \mathrm{e}^{\mathrm{n} . \mathrm{s}}$ & $0.016 \pm 0.001 \mathrm{e}^{\mathrm{n} \cdot \mathrm{s}}$ & $0.033 \pm 0.004 \mathrm{e}^{\mathrm{n} . \mathrm{s}}$ & $0.026 \mathrm{e}^{\mathrm{n} . \mathrm{s}}$ & 0.19 \\
\hline Zeolite & - & - & - & - & $0.047 c d^{n . s}$ & 0.12 \\
\hline Perlite & - & - & - & - & $0.038 \mathrm{~d}^{\mathrm{n} . \mathrm{s}}$ & 0.17 \\
\hline Mean & $0.067 a^{* *}$ & $0.047 b^{n . s}$ & $0.041 b^{n . s}$ & $0.067 a^{* *}$ & & \\
\hline CV & 0.12 & 0.16 & 0.15 & 0.19 & & \\
\hline
\end{tabular}

Generally, all the biochar types and amendment rates increased the amount of water retained at $\mathrm{pF}=0$ and $\mathrm{pF}=1.5$ (Figure 2). Notably, most of the biochar types at the application rates of $5 \%, 10 \%$ and $15 \%(v / v)$ reduced the water held at the DP $(\mathrm{pF}=2.7)$ whilst increasing the FC ( $\mathrm{pF}=1.5)$ because the interactions between the biochar and the sand particles through the aggregation created water-holding pores with greater effectiveness [24]. The difference between the FC and DP represented the RAW capacity, which reduced as a greater biochar application rate was added to the sandy soil. This showed the diminishing ability of biochar to hold water that plants can easily extract, implying that a smaller amount of biochar amendment was of greater benefit.

In Table 2, it can be seen that the RAW for the 5\% and $10 \%(v / v)$ biochar application rates was significantly higher $(p<0.001)$ than the value of the other rates across all the biochar types. The biochar from wood-based feedstocks (WBC and WWBC) significantly increased the WRC of the sandy soil at successive application rates. This was consistent with the report from Kameyama et al. [20]. The biochar from bagasse (BBC) had a nonuniform effect on the WRC even as more biochar was added, whereas PLBC had a minimal difference between the various biochar rates (see Figure 3).

The ability of biochar to affect the hydraulic properties and water retention of agricultural soils is a direct result of its physical properties. Properties such as particle size, bulk density [25], specific surface area [41] and pore size distribution [24] play an essential role in the capacity of biochar-amended soil to hold water. The biochar samples with a larger specific surface area, such as WBC (Table 1), tended to enable a greater amount of water retention [24] (Table 2). This resulted from an increased general porosity, including intraparticle pores and inter-particle pores, due to the sand-biochar aggregation [41]. When biochar and soil particles interact, the volume of inter-particle pores can increase or decrease depending on the particle size and shape of the biochar samples [25]. Ibrahim et al. [41] discovered that a biochar with a particle size of $0.5-1.0 \mathrm{~mm}$ could effectively optimize the WRC of sandy soils. However, this particle size could also negatively affect the WRC of the soil, especially when the particles were feathery and flat in shape. This could explain why the BBC had a lower capacity to hold more water effectively for plant use. The wood-based biochar types had irregular surface shapes that did not interlock with the sand particles, 
thus creating a larger specific surface area and greater number of pores between them for water holding $[21,22,24]$. In part, this justified why WBC and WWBC improved the RAW capacity with a greater significance than the other treatments $(p<0.01)$ (see Table 2).
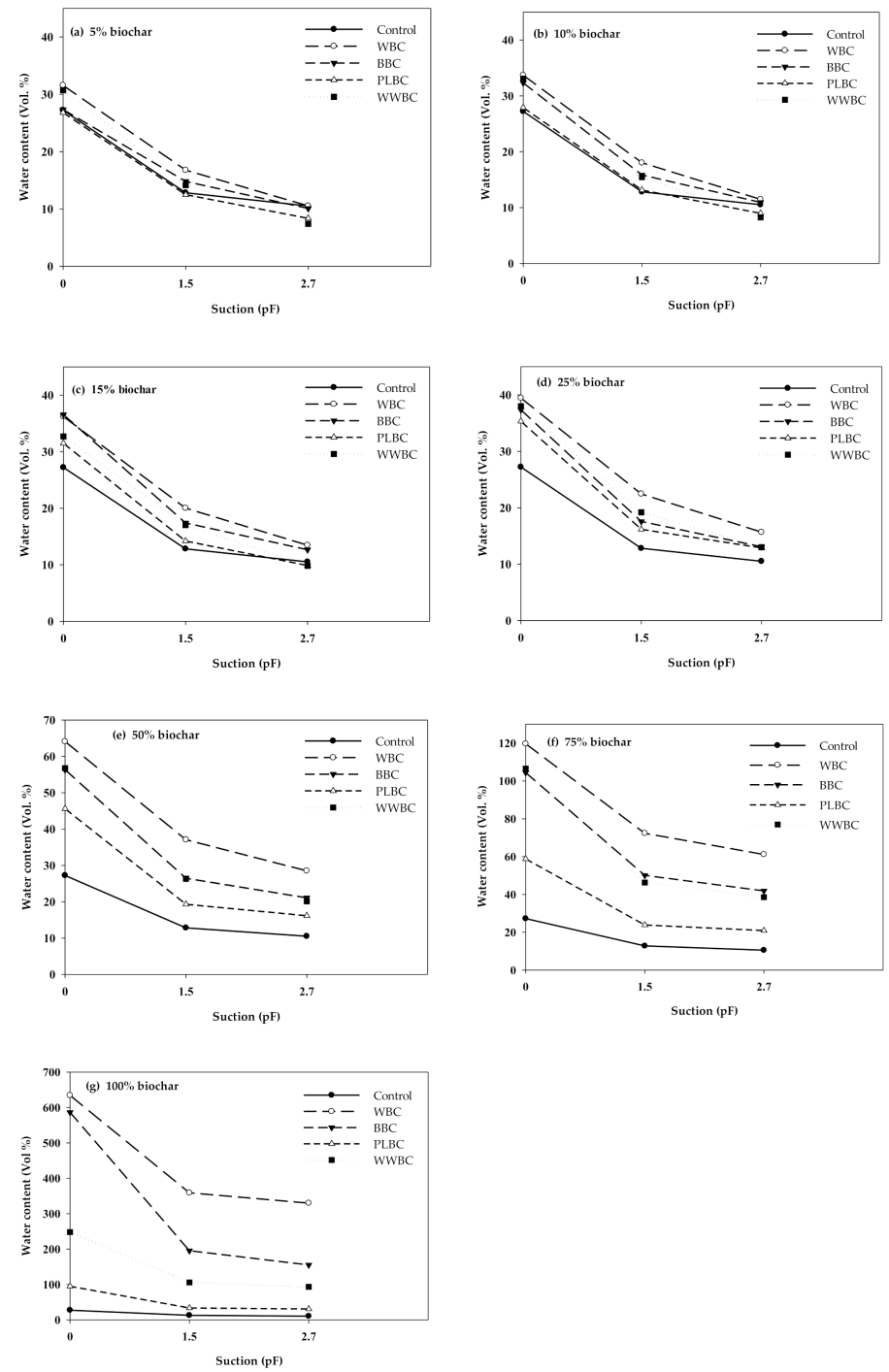

Figure 2. Soil water retention curves for sandy soil amended with woodchip biochar (WBC), bagasse biochar (BBC), poultry litter biochar (PLBC) and waterweed biochar (WWBC) at (a) 5\%, (b) 10\%, (c) $15 \%$, (d) $25 \%$, (e) $50 \%$, (f) $75 \%$ and (g) $100 \%$ biochar rates $(v / v)$.

In this study, we sought to establish how a biochar amendment of sandy soil would affect its capacity to hold water that is easily accessible for an effective uptake by plants. The results, as shown in Table 2, confirmed our hypothesis that biochar could improve the RAW capacity. In almost all the biochar treatments, the RAW increased against the control. It is interesting to note that the effect of the biochar-sand amendment on the RAW capacity was inversely related to the WRC. As the biochar amount increased, there was a general increase in the WRC with a reducing RAW capacity (Figure 3). The RAW capacity peaked at a $5 \%(v / v)$ biochar application with a value of 0.065 and $0.059 \mathrm{~cm}^{3} \mathrm{~cm}^{-3}$ for BBC and PLBC, respectively; at $10 \%(v / v)$, it was 0.085 and $0.094 \mathrm{~cm}^{3} \mathrm{~cm}^{-3}$ for WBC and WWBC, respectively. However, for the latter duo, the difference between the RAW capacity at the $5 \%$ and $10 \%(v / v)$ rates was almost negligible. 

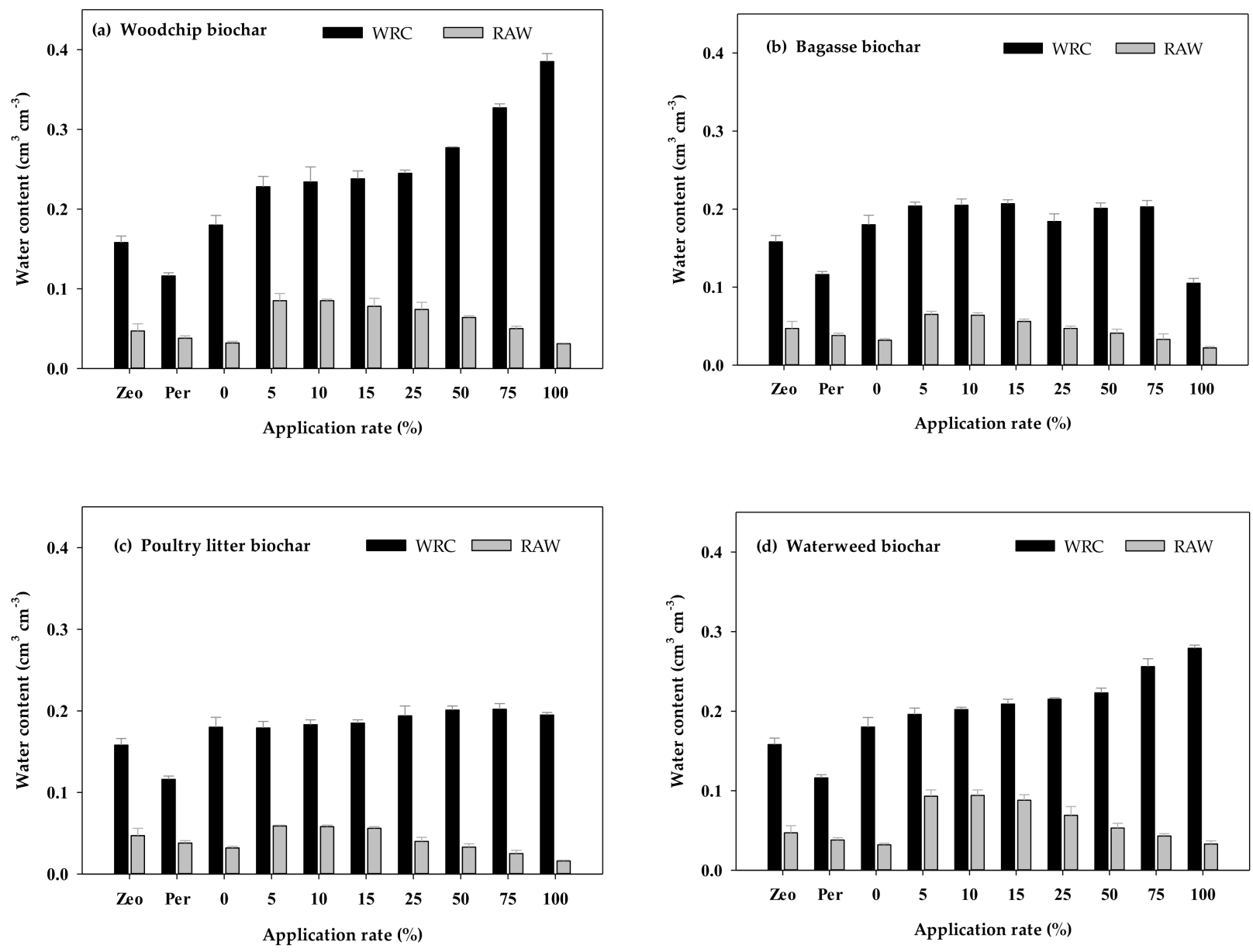

Figure 3. Effect of the biochar rate as well as zeolite and perlite on the water retention capacity (WRC) and the readily available water (RAW) of sandy soil amended with (a) woodchip biochar (WBC), (b) bagasse biochar (BBC), (c) poultry litter biochar (PLBC) and (d) waterweed biochar (WWBC) at $0 \%, 5 \%, 10 \%, 15 \%, 25 \%, 50 \%, 75 \%$ and $100 \%$ biochar rates.

A further analysis revealed that $5 \%$ biochar was generally the optimal rate for the highest RAW capacity ( $p<0.001$ ) except in the case of PLBC, where it caused a negative increment. The reduction affected by PLBC could be associated with an increased bulk density of up to $2.7 \%$ (see Figure 1). Beyond a $5 \%(v / v)$ biochar addition, there was a consistent indication that the volume of the RAW-equivalent pores reduced, a situation that negatively affects the hydraulic conductivity of the soil [42]. An analysis of the intra-particle pore size distribution of the biochar samples revealed that most of the pores were in the micropore range with peak diameters below $2 \mathrm{~nm}$ (see Table 1). A previous study observed that biochar macropores and sand-biochar inter-particle pores play a significant role in improving the RAW of soil [24] and are most effective in such coarse-textured soils.

The RAW figures posted by the biochar amendments at $5 \%$ and $10 \%(v / v)$ were higher $(p<0.001)$ than those affected by commercial conditioners, zeolite and perlite, of 0.047 and $0.038 \mathrm{~cm}^{3} \mathrm{~cm}^{-3}$, respectively (see Table 2). Although the two reduced the WRC of the sandy soil, the capacity to hold RAW was slightly higher but almost insignificant compared with the control. The biochar proved to be superior in availing the retained water for effective plant utilization. However, higher application rates of biochar had a minimal effect on the RAW with a few treatments (such as $75 \%(v / v)$ PLBC) reducing its value by up to $22 \%$ (Figure 4). This indicated that the majority of the water retained was held in micropores and thus not readily available for plant uptake. The addition of large biochar quantities to the sandy soil decreased the inter-particle pores that would have held water less tightly for plant use. 




Amendment material

Figure 4. Effect of biochar type (woodchip biochar (WBC), bagasse biochar (BBC), poultry litter biochar (PLBC) and waterweed biochar (WWBC)), biochar application rate, zeolite and perlite on the incremental RAW capacity of sandy soil (\% volume).

In most cases, the addition of biochar to agricultural soil can improve the ability of that soil to hold a greater amount of water that is readily available for plant uptake. In Figure 4, we illustrate how various biochar treatments affected the RAW increment in sandy soil in this study. There was a general tendency shown by all treatments to increase the RAW capacity except at $100 \%, v / v$ for WBC and BBC and at $75 \%$ and $100 \%$ for PLBC, which caused a reduction of $3.1 \%, 33.3 \%, 22.5 \%$ and $50.4 \%$, respectively. Although biochar is famed for drought mitigation, this could be an indication that biochar may not be advantageous as a standalone planting medium. However, this condition may have been caused by the mechanical crushing of the biochar materials to attain the required particle size of between 0.5 and $1.0 \mathrm{~mm}$. This process causes a damaging effect on the pores and considerably reduces the intra-particle mesopores and macropores necessary to hold water equivalent to the RAW [24,43].

Among the various biochar types, the 5\% (v/v) and $10 \%(v / v)$ applications caused the highest RAW increment with peaks at 5\% (BBC $=101.6 \%$; PLBC $=84.0 \%)$ and $10 \%$ (WBC $=164.6 \% ; \mathrm{WWBC}=191.5 \%$ ), respectively. This was consistent with the findings of Wang et al. [42], who pointed out that beyond a 5\% biochar application comes a diminishing return on the plant-available water. Previously, hydrophobicity has been highlighted as a contributor to a low WRC and RAW in biochar-amended soils [44]. This phenomenon often occurs when certain complex volatile organic compounds stick on the surface of the biochar during the pyrolysis process and is common in fresh biochar [39]. We speculated that this could partly explain why BBC and PLBC, which were both freshly produced biochar, posted lower values (Table 2, Figure 4). It should also be noted that economic viability is an essential concern for the implementation of biochar use in practice [45]. Given that a 100\% biochar addition showed no remarkable effect in our study, it is relevant to recommend lower dosages to end users.

\section{Conclusions}

It is vital to conclude that biochar made from woody feedstocks has a higher capacity to retain more water that is readily available for effective plant use. Biochar is also more 
beneficial to water retention for plant uptake than most of the existing soil conditioners on the market. Zeolite and perlite, two of the most common materials today, cannot easily avail the retained water for plant uptake. Thus, as the impact of global climate change on drought grows, the ability of biochar to hold a greater amount of RAW for longer is useful for improving the situation. Agriculture, particularly rain-reliant, could improve as drought is reduced; irrigated agriculture could experience a reduced irrigation requirement and frequency.

It is advisable to limit biochar addition to sandy soils to below $10 \%(v / v)$ to improve the readily available plant water. As our study revealed that the RAW increments affected by the $5 \%(v / v)$ and $10 \%(v / v)$ biochar applications were almost equal, the former is of optimum economic and technical benefit for farmers. In addition to the soil water hydrologic advantages, this would render biochar useful for increasing and sustaining agricultural productivity.

Author Contributions: Conceptualization, E.O.N.; methodology, E.O.N. and S.K.; software, E.O.N. and O.I.; validation, E.O.N., O.I. and K.J.; formal analysis, E.O.N. and O.I.; investigation, E.O.N.; resources, T.T.; data curation, E.O.N. and S.K.; writing-original draft preparation, E.O.N.; writing-review and editing, E.O.N., O.I. and K.J.; visualization, E.O.N.; supervision, S.K. and K.J.; project administration, T.T.; funding acquisition, T.T. All authors have read and agreed to the published version of the manuscript.

Funding: This study was conducted during an internship program at Meiwa Co., Ltd. under the ABE Initiative of JICA. There was no dedicated financial support to the processes leading to this activity thus it was no funding number.

Data Availability Statement: Not applicable.

Acknowledgments: The study was supported by the Japan International Corporation Agency (JICA) and Meiwa Co., Ltd. through the African Business Education (ABE) Initiative for Youth program. Meiwa Co., Ltd. supported this research by providing materials and equipment and, to an extent, technical support. The authors would like to thank the staff of these organizations for making this study a success. We also appreciate Professor Tsugiyuki Masunaga (Shimane University, Japan) for his support in the analysis of the soil texture, surface area and peak pore size of the biochar samples. Keiji Jindo wishes to acknowledge financial support (3710473400). This research did not receive any specific grant from funding agencies in the public, commercial or not-for-profit sectors.

Conflicts of Interest: The authors declare no conflict of interest.

\section{References}

1. Intergovernmental Panel on Climate Change. The Physical Science Basis. Contribution of Working Group I to the Fourth Assessment Report of the Intergovernmental Panel on Climate Change; Solomon, S., Qin, D., Manning, M., Chen, Z., Marquis, M., Averyt, K.B., Tignor, M., Miller, H.L., Eds.; Cambridge University Press: Cambridge, UK; New York, NY, USA, 2007; p. 996.

2. Knox, J.; Hess, T.; Daccache, A.; Wheeler, T. Climate change impacts on crop productivity in Africa and South Asia. Environ. Res. Lett. 2012, 7, 034032. [CrossRef]

3. United Nations, Department of Economic and Social Affairs, Population Division. World Population Prospects 2017-Data Booklet; United Nations, Department of Economic and Social Affairs, Population Division: New York, NY, USA, 2017.

4. Food and Agricultural Organization. Climate Smart Agriculture: Sourcebook, 1st ed.; Food and Agricultural Organization of the United Nations: Rome, Italy, 2013.

5. Xiubin, H.; Zhanbin, H. Zeolite application for enhancing water infiltration and retention in loess soil. Resour. Conserv. Recycl. 2001, 34, 45-52. [CrossRef]

6. Wiedefeld, B. Zeolite as a soil amendment for vegetable production in the Lower Rio Grande Valley. Subtropical Plant Sci. 2003, 55, 7-10.

7. Abed-Koupai, J.; Eslamian, S.S.; Kazemi, J.A. Enhancing the available water content in unsaturated soil zone using hydrogel, to improve plant growth indices. Ecohydrol. Hydrobiol. 2008, 8, 3-11.

8. Torkashvand, A.M.; Shadparvar, V. Effect of some organic waste and zeolite on water holding capacity and PWP delay of soil. Current Biotica 2013, 6, 459-465.

9. Dehkordi, K.D. Effect of superabsorbent polymer on salt and drought resistant of Eucalyptus globulus. Appl. Ecol. Environ. Res. 2017, 15, 1791-1802. [CrossRef]

10. Abobatta, W. Impact of hydrogel polymer in agricultural sector. Adv. Agric. Environ. Sci. 2018, 1, 59-64. [CrossRef]

11. Frantz, J.; Locke, J.; Pitchay, D.; Krause, C. Actual performance versus theoretical advantages of polyacrylamide hydrogel throughout bedding plant production. HortiScience 2005, 40, 2040-2046. [CrossRef] 
12. Lehmann, J.; Joseph, S. Biochar for Environmental Management: Science, Technology and Implementation, 2nd ed.; Earthscan, Routledge: London, UK, 2015; pp. 1-13.

13. Avellan, T.; Roidt, M.; Emmer, A.; Von Koerber, J.; Schneider, P.; Raber, W. Making the water-soil-waste nexus work: Framing the bounderies of resource flow. Sustainability 2017, 9, 1881. [CrossRef]

14. Singh, D.P.; Prabha, R.; Renu, S.; Sahu, P.K.; Singh, V. Agrowaste bioconversion and microbial fortification have prospects for soil health, crop productivity, and eco-enterprising. Int. J. Recycl. Org. Waste Agric. 2019, 8, 457-472. [CrossRef]

15. Sikder, S.; Joardar, J.C. Biochar production from poultry litter as management approach and effects on plant growth. Int. J. Recycl. Org. Waste Agric. 2019, 8, 47-58. [CrossRef]

16. Woolf, D.; Amonette, J.E.; Street-Perrott, F.A.; Lehmann, J.; Joseph, S.G. Sustainable biochar to mitigate global climate change. Nat Commun. 2010, 1, 56. [CrossRef] [PubMed]

17. Kinney, T.J.; Masiello, C.A.; Dugan, B.; Hockaday, W.C.; Dean, M.R.; Zygourakis, K.; Barnes, R.T. Hydrologic properties of biochars produced at different temperatures. Biomass- Bioenergy 2012, 41, 34-43. [CrossRef]

18. Jeffery, S.; Verheijen, F.G.A.; van der Velde, M.; Bastos, A.C. A quantitative review of the effects of biochar application to soils on crop productivity using meta-analysis. Agric. Ecosyst. Environ. 2011, 144, 175-187. [CrossRef]

19. Biederman, L.A.; Harpole, W.S. Biochar and its effects on plant productivity and nutrient cycling: A meta-analysis. GCB Bioenergy 2013, 5, 202-214. [CrossRef]

20. Kameyama, K.; Iwata, Y.; Miyamoto, T. Biochar Amendment of Soils According to their Physicochemical Properties. Jpn. Agric. Res. Quarterly: JARQ 2017, 51, 117-127. [CrossRef]

21. Blanco-Canqui, H. Biochar and Soil Physical Properties. Soil Sci. Soc. Am. J. 2017, 81, 687-711. [CrossRef]

22. Mukome, F.N.D.; Zhang, X.; Silva, L.; Six, J.; Parikh, S.J. Use of Chemical and Physical Characteristics to Investigate Trends in Biochar Feedstocks. J. Agric. Food Chem. 2013, 61, 2196-2204. [CrossRef] [PubMed]

23. Chatterjee, R.; Sajjadi, B.; Chen, W.-Y.; Mattern, D.L.; Hammer, N.; Raman, V.; Dorris, A. Effect of Pyrolysis Temperature on PhysicoChemical Properties and Acoustic-Based Amination of Biochar for Efficient $\mathrm{CO}_{2}$ Adsorption. Front. Energy Res. 2020, 8,8 [CrossRef]

24. Masiello, C.A.; Dugan, B.; Brewer, C.E.; Spokas, K.A.; Novak, J.M.; Liu, Z.; Sorrenti, G. Biochar effects on soil hydrology. In Biochar for Environmental Management: Science, Technology and Implementation, 2nd ed.; Lehmann, J., Joseph, S., Eds.; Earthscan, Routledge: London, UK, 2015; pp. 543-562.

25. Liu, Z.; Dugan, B.; Masiello, C.A.; Gonnermann, H.M. Biochar particle size, shape and porosity act together to inflluence soil water properties. PLoS ONE 2017, 12, e0179079.

26. Basso, A.S.; Miguez, F.E.; Laird, D.A.; Horton, R.; Westgate, M. Assessing potential of biochar for increasing water-holding capacity of sandy soils. GCB Bioenergy 2013, 5, 132-143. [CrossRef]

27. Yu, O.-Y.; Raichle, B.; Sink, S. Impact of biochar on the water holding capacity of loamy sand soil. Int. J. Energy Environ. Eng. 2013, 4, 44. [CrossRef]

28. Liu, Z.; Dugan, B.; Masiello, C.; Barnes, R.T.; Gallagher, M.E.; Gonnermann, H. Impacts of biochar concentration and particle size on hydraulic conductivity and DOC leaching of biochar-sand mixtures. J. Hydrol. 2016, 533, 461-472. [CrossRef]

29. Koide, R.T.; Nguyen, B.; Skinner, R.H.; Dell, C.J.; Peoples, M.S.; Adler, P.R.; Drohan, P.J. Biochar amendment of soil improves resilience to climate change. GCB Bioenergy 2014, 7, 1084-1091. [CrossRef]

30. Hansen, V.; Hauggaard-Nielsen, H.; Petersen, C.T.; Mikkelsen, T.N.; Müller-Stöver, D. Effects of gasification biochar on plantavailable water capacity and plant growth in two contrasting soil types. Soil Tillage Res. 2016, 161, 1-9. [CrossRef]

31. De Melo-Carvalho, M.T.; De Holanda Nures Maia, A.; Madari, B.E.; Bastiaans, L.; Van Oort, P.A.J.; Heinemann, A.B.; Soler Da Silva, M.A.; Petter, F.A.; Marimon, B.H., Jr.; Meinke, H. Biochar increases plant-available water in a sandy loam soil under an aerobic rice crop system. Solid Earth 2014, 5, 939-952. [CrossRef]

32. Gee, G.W.; Bauder, J.W. Particle-size Analysis. In Methods of Soil Analysis: Part 1-Physical and Mineralogical Methods, 2nd ed.; Klute, A., Ed.; Agronomy Monographs, ASA and SSSA: Madison, WI, USA, 1986; pp. 383-411.

33. Ministry of Agriculture, Forestry and Fisheries (MAFF). Available online: http://www.maff.go.jp/j/seisan/kankyo/hozen_ type/h_sehi_kizyun/attach/pdf/tottori01-9.pdf (accessed on 25 June 2018).

34. Rajkovich, S.; Enders, A.; Hanley, K.; Hyland, C.; Zimmerman, A.R.; Lehmann, J. Corn growth and nitrogen nutrition after additions of biochars with varying properties to temperate soil. Biol. Fertil. Soils 2012, 48, 271-284. [CrossRef]

35. Sun, X.; Shan, R.; Li, X.; Pan, J.; Liu, X.; Deng, R.; Song, J. Charaterization of 60 types of Chinese biomass waste and resultant biochars in terms of their candidacy for soil application. GCB Bioenergy 2015, 9, 1423-1435. [CrossRef]

36. Abel, S.; Peters, A.; Trinks, S.; Schonsky, H.; Facklam, M.; Wessolek, G. Impact of biochar and hydrochar addition on water retention and water repellency of sandy soil. Geoderma 2013, 202, 183-191. [CrossRef]

37. Gamage, D.V.; Mapa, R.B.; Dharmakeerthi, R.S.; Biswas, A. Effect of rice-husk biochar on selected soil properties in tropical Alfisols. Soil Res. 2016, 54, 302-310. [CrossRef]

38. Obia, A.; Mulder, J.; Martinsen, V.; Cornelissen, G.; Børresen, T. In situ effects of biochar on aggregation, water retention and porosity in light-textured tropical soils. Soil Till. Res. 2016, 155, 35-44. [CrossRef]

39. Mollinedo, J.; Schumacher, T.E.; Chintal, R. Influence of feedstocks and pyrolysis on biochars capacity to modify soil water retention characteristics. J. Anal. Appl. Pyrol. 2015, 114, 100-108. [CrossRef] 
40. Ma, N.; Zhang, L.; Zhang, Y.; Yang, L.; Yu, C.; Yin, G.; Doane, T.A.; Wu, Z.; Zhu, P.; Ma, X. Biochar improves soil aggregate stability and water availability in a Mollisol after three years of field application. PLoS ONE 2016, 11, e0154091. [CrossRef] [PubMed]

41. Ibrahim, A.; Usman, A.R.A.; Al-Wabel, M.I.; Nadeem, M.; Al-Osman, A. Effect of Conocarpus biochar on hydraulic properties of calcarious sandy soil: Influence of particle size and application depth. Arch. Agron. Soil Sci. 2017, 63, 185-197. [CrossRef]

42. Wang, D.; Li, C.; Parikh, S.J.; Scow, K.M. Impact of biochar on water retention of two agricultural soils-A multi-scale analysis. Geoderma 2019, 340, 185-191. [CrossRef]

43. Liao, W.; Thomas, S.C. Biochar particle size and post-pyrolysis mechanical processing affects soil $\mathrm{pH}$, water retention capacity and plant performance. Soil Syst. 2019, 3, 1-16. [CrossRef]

44. Zornoza, R.; Moreno-Barriga, F.; Acosta, J.A.; Munoz, M.A.; Faz, A. Stability, nutrient availability and hydrophobicity of biochars derived from manure, crop residues, and municipal solid waste for their use as soil amendments. Chemosphere 2015, 144, 122-130. [CrossRef]

45. Schmidt, H.; Anca-Couce, A.; Hagemann, N.; Werner, C.; Gerten, D.; Lucht, W.; Kammann, C. Pyrogenic carbon capture and storage. GCB Bioenergy 2018, 11, 573-591. [CrossRef] 